\title{
Is Hypoperfusion an Important Cause of Strokes? If So, How?
}

\author{
Louis R. Caplan ${ }^{a}$ Ka Sing Wong ${ }^{b}$ Shan Gao ${ }^{c}$ Michael G. Hennerici ${ }^{d}$ \\ ${ }^{a}$ Department of Neurology, Beth Israel Deaconess Medical Center, Boston, Mass., USA; \\ ${ }^{b}$ Department of Medicine and Therapeutics, Chinese University of Hong Kong, Hong Kong, China; \\ ${ }^{\mathrm{c}}$ Department of Neurology, Peking Union Medical College Hospital, Beijing, China; \\ ${ }^{\mathrm{d}}$ Department of Neurology, University of Heidelberg, Klinikum Mannheim, Mannheim, Germany
}

\section{Key Words}

Hypoperfusion · Embolism • Borderzone infarction •

Washout syndrome $\cdot$ Low perfusion syndrome

\begin{abstract}
Traditionally hypoperfusion and embolism are considered separate important causes of stroke in patients with arterial occlusive disease. However, although hypoperfusion and embolism differ in mechanisms and location, they generally coincide in severe obstructive lesions and cause washout disturbances of embolism in low perfusion territories distal to stenosis. Unless the collateral blood supply is sufficient to prevent ischemia, multiple remote spot-like infarctions occur within the hypoperfused brain territory. In border-zone distributed infarction - long suspected to result from hemodynamic compromise alone - complementary interaction of embolisation and hypoperfusion territories has to be considered. Thus hypoperfusion with embolism or embolism alone are the most common explanations for stroke, the former often associated with less severe clinical deficits than the latter.
\end{abstract}

\section{Introduction}

Clinicians and researchers have for more than half a century tried to separate hypoperfusion from embolism as an important cause of stroke in patients with cervicocranial arterial occlusive disease. During the middle years of the 20th century, most brain infarcts were attributed to reduced blood flow (hypoperfusion) caused by obstruction of extracranial and intracranial large and small arteries. Clearly, in all circumstances, a prolonged failure to deliver oxygen and sugar-rich blood to brain tissue causes cell death. Blockage of a microscopic-sized penetrating artery causes severe local decreased perfusion to the small region supplied by the obstructed penetrating artery. Blockage of a distal branch of an intracranial artery by embolic material causes infarction of the limited tissue supplied by that branch.

The debate surrounds the importance of hypoperfusion that results in diminished blood flow at a distance from vulnerable brain tissue, for example, in the carotid or vertebral arteries in the neck or even in the intracranial internal carotid, middle cerebral and intracranial vertebral arteries. Brain embolism refers to blockage of an artery by particulate substances generated proximally

\section{KARGER}

Fax +4161306 1234 E-Mailkarger@karger.ch www.karger.com
Prof. Michael Hennerici, MD

Department of Neurology, University of Heidelberg, Klinikum Mannheim

DE-68135 Mannheim (Germany)

Tel. +496213832885, Fax +496213833807

E-Mail Hennerici@neuro.ma.uni-heidelberg.de 
that move craniad to occlude vessels at the very site of ischemia. Hypoperfusion and embolism differ by mechanism and location. Does occlusive vascular disease in the neck and in the large intracranial arteries cause important brain infarction by reducing intracranial blood flow, by creating emboli that block an intracranial artery or arteries, or by complementary interactions between hypoperfusion and embolism?

\section{Most Clinical Experience Shows that Hypoperfusion Alone Related to Systemic Hypoperfusion or Occlusive Disease at a Distance from the Brain Is Benign}

The weight of data suggests that in most instances hypoperfusion caused by a process at a distance from the brain (for example, the heart or neck arteries) causes either no symptoms or attacks of transient brain ischemia without causing major brain infarction. Cardiac arrest and systemic hypoperfusion even for 10-15 min are rarely associated with large border-zone infarcts even when neuronal ischemia in vulnerable areas has developed.

Most patients with severe stenosis or occlusion of the carotid and/or vertebral arteries in the neck do not develop important strokes. Internal carotid artery (ICA) occlusion is often asymptomatic. The annual rate of stroke in patients with even severe asymptomatic ICA occlusive disease is only $2-3 \%$, so that each year $>95 \%$ of these patients do not develop a stroke [1]. In the 1950s and 1960s a common treatment for brain aneurysms was tying the cervical or intracranial artery that supplied the aneurysm. In the great majority of instances no persistent symptoms developed. When L.R.C. was a house officer during the 1960s, one of his tasks was to gradually ratchet-closed a Selverstone clamp that had been surgically placed around the ICA in the neck in patients who had subarachnoid hemorrhages and intracranial aneurysms. Only about 1 in 10 patients had even transient brain ischemic symptoms and none developed a brain infarct.

During carotid endarterectomy, the carotid artery is occluded, often for 15-30 min, without causing infarction. Acute dissection of the carotid artery in the neck causing severe vascular obstruction often causes brief transient attacks of monocular blindness or cerebral hemisphere symptoms. Brain infarction does not usually develop unless a thromboembolus travels intracranially. However, decreased blood flow caused by a lesion directly at the site of vulnerable brain tissue is not benign. Oc- clusion of penetrating arteries by a lipohyalinotic process $[2,3]$ and narrowing of the orifice of penetrating arteries by atheromatous branch disease [4-7] often cause an infarct directly in the center of perfusion of the obstructed artery. Severe intracranial arterial occlusive disease also is much more likely to cause brain infarction than extracranial occlusive disease [8-10]. The closer arterial obstruction is to the brain, the more likely that it will result in brain infarction.

\section{How Is the Benignity of Hypoperfusion at a Distance Explained?}

When an artery occludes, the territory it supplies becomes acutely deficient in energy supply. The altered metabolism that develops in the ischemic zone leads to local vasodilatation and the development of collateral circulation that augments flow to the ischemic zone. The pressure in the intracranial arteries fed by the occluded artery is also acutely reduced. The reduced flow may produce a vacuum-like effect that encourages and attracts collateral blood flow.

When L.R.C. was a neurology resident, his chairman and mentor Prof. Derek Denny-Brown allowed him and others to observe experimental work on primates. He performed a craniotomy and opened the dura so that the pial vessels became readily visible. Then he occluded a neck artery. The brain region supplied by the occluded artery blanched and blood flow would be momentarily decreased. Almost immediately new collateral vessel flow began to be visible and supply the region that a moment before had grossly diminished blood flow. Ischemia itself induces collateral blood flow, especially when supply arteries are occluded slowly as is usually the case in atherosclerotic occlusive disease. The gradual narrowing of an artery gives ample time and stimulus for the development of adequate collateral blood flow.

Similarly, compression testing during ultrasound studies in patients with severe ( $>80 \%$ narrowing) extracranial ICA occlusive disease results in immediate increase in collateral blood flow $[11,12]$. Collateral flow is derived from preexisting channels: external carotid-ICA (ophthalmic and maxillary arteries), ICA-ICA (through the anterior communicating and anterior cerebral arteries in the anterior portion of the circle of Willis), and through vertebrobasilar-ICA communications (posterior communicating and posterior cerebral arteries in the posterior portion of the circle of Willis). The rapid increase in blood flow occurred even when the common carotid or ICA 
contralateral to a completely occluded ICA was compressed. Neurological symptoms develop only when an embolus is dislodged during the compression maneuver, an occurrence that can be avoided by prior ultrasound display of the artery.

\section{Experience Shows that Embolism Is a Common Explanation for Severe Strokes}

Emboli of cardiac origin are a frequent cause of large brain infarcts and hemorrhagic brain infarcts [13-16]. In the Stroke Data Bank, the medium volume of infarction on $\mathrm{CT}$ in patients with cardiac origin embolism was 2.4 times that found in patients who had cervical arterial disease, a highly significant difference $(p<0.01)$ [16].

Atrial fibrillation is now recognized as the most frequent cardiac source of brain emboli and a very important cause of brain infarction overall. Often the initial stroke is large and disabling $[17,18]$. Brain embolism related to myocardial infarction and valvular heart disease is also known to be a cause of significant brain infarction.

Ringelstein et al. [19] analyzed the distribution and size of infarcts in patients with carotid artery occlusive disease using brain imaging and cerebral angiography. Those patients that had artery-to-artery embolism to the middle cerebral artery (MCA, occlusio supra occlusionem) had larger brain infarcts than those who did not have intra-arterial emboli. Early cerebral angiography during the first $6 \mathrm{~h}$ after the onset of brain ischemic symptoms shows that about $80 \%$ of angiograms have an intracranial occlusion that is almost invariably embolic [20, 21].

The explanation of why emboli are likely to cause brain infarction is explained by the rapidity of the occlusion and the size of the embolus. When emboli block distal branch arteries, collateral blood flow through anastomotic channels is less efficient and slower than when these branches remain patent. Sudden intracranial artery occlusion leaves considerably less time for the development of collateral flow than gradual occlusion. The blockage is also closer to the region of ischemia leaving less opportunity for collateralization from proximal arteries. Thrombi formed in the heart are usually larger than those that develop in narrowed arteries, explaining why brain infarcts caused by cardiac-origin emboli are on average larger than emboli that originate in proximal arteries.

Is Hypoperfusion an Important Cause of Stroke?

\section{Imaging and Ultrasound Monitoring Data Shows that the Prevalence of Embolism Is Higher than Previously Suspected}

Transcranial Doppler ultrasound (TCD) monitoring has now shown that signals identified in the Fast Fourier Transformation (FFT) of the spectrum may represent 'microembolic' particles and are very often detectable in patients with potential sources of embolism, although they hardly ever cause any associated clinical events [2230]. Thus, these signals should be described as high-intensity transient signals (HITS) within the Doppler spectra rather than microembolic signals.

HITS are often found in patients with symptomatic carotid artery disease, especially when the stenosis is severe and the patients have recently had eye or cerebral ischemic symptoms [29-32]. The number of HITS declines with time after ischemic events [33, 34], after carotid artery surgery [35], and after antiplatelet and anticoagulant treatment [35-37].

Most neurologists are well aware that HITS occur in patients with ICA occlusive disease in the neck. However, knowledge about embolism in patients with stenosis of the intracranial ICAs and MCAs is more limited. Recent studies show that HITS are often detectable in symptomatic patients with severe intracranial ICA and MCA stenosis [38-40]. Wong et al. [38] used TCD to monitor for HITS in 114 patients with moderate or severe MCA stenosis diagnosed using MRA and TCD. Patients with ICA disease and those with potential cardiac and aortic embolic sources were excluded. HITS were found in 25/114 (21\%) and correlated with the severity of the MCA stenosis. Those with severe stenosis had more than twice the frequency of HITS detection compared to those with slight to moderate stenosis. Among symptomatic patients followed for an average of 13.6 months a significant association (log rank 5.96, $\mathrm{p}=0.01$ ) was found between the presence of HITS and further strokes [38, 39]. Segura et al. [40] reported a patient with a high-grade MCA stenosis in whom ischemic symptoms correlated with clusters of HITS that occurred with a frequency of 8 clusters per hour with each cluster containing 12-45 microembolic signals.

HITS are also often found in patients with potential cardiac sources of emboli [30]. Patients with atrial fibrillation, those with coronary atherosclerotic heart disease with ejection fractions of $<30 \%$, dilated cardiomyopathy, and valvular heart disease have the highest frequency. However, quite often these signals are produced by microgaseous cavitations that can be differentiated from solid

Cerebrovasc Dis 2006;21:145-153 
thromboembolic material detected during and shortly after cardiac surgery $[26,27]$. Many HITS are detected in the MCAs and in the lumen of the aorta during and after cardiac surgery when patients are monitored using TCD and transesophageal echocardiography [41-45]. Most microembolic particles are recorded during clamping and unclamping of the aorta, but flurries of emboli are also detected during cannulation of the aorta and at the beginning and end of cardiac bypass. HITS are also often detected during cerebral catheter angiography, cerebrovascular and contrast media interventions (stenting of the carotid system) and coronary angioplasty [46]. Particles related to HITS are of diverse composition and probably consist of air microbubbles, atheromatous debris, lipid, and platelet-fibrin thrombi. Necropsy studies of patients and experimental animals who died after heart surgeries that included cardiopulmonary bypass show that the brains contain millions of small capillary and arteriolar dilatations thought to represent sites of microembolization [43]. Cardiac and aortic origin embolism undoubtedly contribute to the brain damage often noted after cardiac surgery - whether this also happens during carotid endarterectomy/angioplasty is a matter of discussion.

The foregoing data leads to the inescapable conclusion that embolism of different components is the major dominant cause of brain infarction. Embolism often remains clinically silent even when occurring as showers of HITS; however, HITS are a reliable indicator of an increased risk of development of brain infarction even though they do not necessarily represent microemboli and are clinically silent. Embolism clearly trumps hypoperfusion as the major cause of brain infarction.

\section{Recent Observations Strongly Support an Important Correlation between the Severity of Occlusive Disease Causing Hypoperfusion and Ischemic Strokes}

\section{Severity of Arterial Stenosis}

Severity of stenosis is widely accepted as the major prognostic stroke risk factor in patients with symptomatic and asymptomatic ICA disease in the neck [1, 4751]. Increasing severities of stenosis place hemodynamic stress on the brain circulation. Hennerici et al. [1] and Chambers and Norris [47] found increasing frequencies of transient ischemia and stroke in relation to increasing grades of ICA stenosis among asymptomatic patients. This finding was not observed in more recent trials (Asymptomatic Carotid Artery Surgery Study [52] and the Asymptomatic Carotid Surgery Trial [53]) due to the limited design of ultrasound protocols. In contrast, the North American Symptomatic Carotid Endarterectomy Trial [48] and the European Carotid Surgery Trial [49] showed that the stroke risk correlated highly with the severity of ICA stenosis in patients with transient monocular blindness, transient hemispheral ischemic attacks, and minor strokes. The major advantage of surgery combined with aspirin therapy over medical therapy in the carotid surgery trials was early correction of reduced blood flow caused by the ICA obstruction ( $>70 \%$ stenosis) since medical therapy was similar in the medical and surgical treatment groups. Aspirin should theoretically reduce thromboembolism equally in both groups. Brain scans of patients with asymptomatic and symptomatic carotid artery disease show that patients with severe stenosis and occlusion have more frequent brain infarcts, more 'silent infarcts' on MRI, and larger brain infarcts than those with minor degrees of carotid narrowing [5053]. The severity of intracranial arterial stenosis also relates to the probability of developing brain infarction [9, 54-56].

\section{Cerebrovascular Reserve and Collaterals in ICA \\ Stenosis and Occlusion Patients}

Cerebrovascular reserve measurements provide reliable information about the ability of the circulation to alter blood flow in response to various physiologic and pharmacologic stimuli. Patients with limited reserve have less adequate perfusion capability than patients with normal reserve irrespective of proximal obstructive lesions. Patients with poor reserve have more strokes and more internal border-zone infarcts than when reserve is preserved. Patients symptomatic with ICA stenosis have shown reduced vasomotor reactivity compared to asymptomatic patients with similar severity of stenosis [57]. When $\mathrm{CO}_{2}$ reactivity was measured using TCD, reduced cerebrovascular reserve correlated with the presence and size of internal border-zone infarcts [58, 59]. The collateral vascular network and reserve capacities crucially depend on the anatomy and integrity of the circle of Willis and probably adapt with time [60]. This makes reliable predictions about the prognosis of individual patients very difficult when follow-up studies are available.

\section{Collateral Circulation in Patients Given \\ Thrombolytic Agents}

In search of indicators of outcome after thrombolysis, investigators have identified the presence and adequacy of collateral circulation supplying the brain distal to arte- 
rial occlusions as a key prognostic factor. In all studies delayed recanalization and poor collateral vessels correlated with poor outcome when compared to early recanalization and good collaterals [61-63]. Rapid recanalization and the presence of good collateral circulation predicts the development of small infarcts while patients with delayed or absent recanalization and poor collaterals develop larger infarcts [61]. Von Kummer and Forsting [62] analyzed the results among 53 patients with angiographically proven MCA trunk occlusions treated with intravenous or intra-arterial recombinant tissue plasminogen activator and heparin. Preserved collateral blood supply correlated with less severe brain edema on initial $\mathrm{CT}$, and after successful thrombolysis that resulted in recanalization at 8 and $24 \mathrm{~h} \mathrm{[62].} \mathrm{Others} \mathrm{have} \mathrm{also} \mathrm{shown}$ that collateral circulation and early reperfusion are relatively protective in patients with ICA [63], MCA [64], and basilar artery $[65,66]$ occlusions treated with thrombolytic agents. Recanalization and effective collateral blood supply help clear small thromboemboli from the cranial circulation.

\section{Association of Reduced Perfusion with Brain}

\section{Infarction after Cardiac Surgery}

Brain perfusion during cardiac surgery is also an important factor in predicting the presence and severity of ischemic brain damage after surgery [4]. Among 100 cardiopulmonary bypass surgery patients, Tufo et al. [67] found neurological signs in $78 \%$ of patients whose mean arterial pressure was maintained at $40 \mathrm{~mm} \mathrm{Hg}$ during surgery but in only $27 \%$ of those whose mean pressure was $60 \mathrm{~mm} \mathrm{Hg}$. The duration of hypotension below $60 \mathrm{~mm} \mathrm{Hg}$ averaged $46 \mathrm{~min}$ in patients with neurologic signs compared to $21 \mathrm{~min}$ in those without signs. In another study, the importance of both the severity and duration of hypotension below a mean arterial pressure of $50 \mathrm{~mm} \mathrm{Hg}$ were important factors in the development of neurological abnormalities after cardiac surgery [68]. In a randomized study, patients whose mean arterial pressure was maintained in the $50-60 \mathrm{~mm} \mathrm{Hg}$ range had a stroke frequency of $7.2 \%$ compared to $2.4 \%$ in patients whose mean arterial pressures were maintained in the 80-100 mm Hg range [69].

\section{Border-Zone Infarcts and Hypoperfusion}

After cardiac arrest or prolonged hypotension, brain imaging and necropsy often show infarction in the border zones between the major brain-supplying intracranial ar- teries [70-74]. Border-zone areas have also been called watershed zones or distal fields. The most common location of infarcts is bilateral between the posterior cerebral arteries and MCAs in the parietal and temporal lobes. Sometimes they are located in the frontal lobe between the anterior cerebral arteries and MCAs and in the cerebellum between the anterior inferior, posterior inferior, and superior cerebellar arteries. Many small infarcts are distributed bilaterally within the brain border-zone regions between the cerebral and cerebellar arteries $[43,74]$. Bilateral border-zone distribution has traditionally been attributed to systemic hypoperfusion. However, the anatomy of the arterial border zones varied greatly when studied post mortem [75] and most recently with MRI [76]. The border zones, especially those that are subcortical, also vary greatly in patients with different severities of extracranial arterial stenosis [77], and different mechanisms reflect similar topographies in subcortical territories [78]. Thus the original concept of arterial border zones proposed by Zülch [71] and Zülch and Behrend [72] in the mid 1950s and later reinforced by others [73, 74] is probably valid in only a few patients and is likely only rarely explained by hemodynamic compromise alone [79-82].

\section{Border-Zone Infarcts and Embolism}

Information has been accumulating that border-zone distribution infarction can be related to embolization and is not always attributable to hypoperfusion alone. In a seminal report on border-zone infarction, Romanul and Abramowicz [73] described the necropsy findings in 3 patients who had episodes of severe hypotension and patent neck arteries and 5 patients with carotid artery occlusions in the neck. All had border-zone distribution infarcts, bilateral in the group with patent neck arteries, and predominantly unilateral in patients with unilateral carotid occlusions in the neck. The small pial vessels within the border zones appeared chalky white. Microscopic sections showed occlusion of the pial arteries within the border zones by closely packed clumps of platelets, often admixed with leukocytes. Romanul and Abramowicz [73] interpreted the findings as indicating local in situ platelet thrombi formation promoted by hypoperfusion. At the time of their report (1974), hypoperfusion was the popular and the predominant explanation for most brain infarction. In retrospect their findings could just as well be explained by white platelet emboli. 
Necropsy studies have shown that cholesterol crystal emboli can be found within vessels in the brain within arterial border zones. In 1970 Price and Harris [83] found extensive cholesterol emboli within bilateral border zones in a patient who died after cardiac surgery. They attributed the origin of the cholesterol emboli to retrograde perfusion of the aorta during surgery. Beal et al. [84] found cholesterol crystals within vessels in arterial border zones of the right cerebral hemisphere at necropsy in a patient who during life had had multiple transient ischemic attacks and fixed deficits in whom angiography had identified an ulcerated plaque in the right ICA in the neck. Masuda et al. [85] analyzed the distribution and pathology among 15 patients with brain atheromatous embolism studied clinically and at necropsy. Heart surgery, cardiac catheterization, and angiography triggered embolism in $6(40 \%)$ of these patients. Nine $(60 \%)$ patients had extensive cortical, often hemorrhagic, infarcts in the regions of the arterial border zones between the anterior cerebral artery and MCA and between the middle and posterior cerebral arteries. All patients had complicated atheromas in the ascending aorta and the aortic arch. Cholesterol crystal emboli were often found in arteries within the border-zone regions.

Anatomical studies in patients and experimental animals have shown microemboli within vessels in arterial boundary zones. The size of the embolic material is an important consideration [83-89]. Cholesterol and whiteplatelet emboli are small enough to traverse the larger arteries and travel as far as small arterioles and capillaries.

Modern clinical and imaging studies also show that embolism is often detectable in patients with border-zone infarcts. Belden et al. [90] studied patients with borderzone distribution infarcts between the middle and posterior cerebral arteries. Most patients had embolic sources and embolism was the most frequent cause of the infarcts.

Caplan and Hennerici [91] reported a patient who developed many transient left cerebral hemisphere ischemic attacks. He had severe ( $>80 \%$ luminal narrowing) stenosis of the left ICA in the neck. During TCD monitoring, $>5$ HITS per hour were recorded over the left MCA. Diffusion-weighted MRI imaging showed small areas of altered signals representing focal regions of edema along the subcortical border-zone regions between the MCA and the anterior and posterior cerebral arteries [89].

Wong et al. [38] prospectively studied 30 consecutive acute ischemic stroke patients with MCA stenosis. Diffu- sion-weighted MRI imaging showed that $11(37 \%)$ had multiple chain-like small infarcts within the border-zone regions supplied by the stenotic MCA. Nine of these 11 patients had multiple microembolic signals detected by TCD monitoring of the stenotic arteries. The number of microembolic signals predicted the number of acute infarcts seen on diffusion-weighted MRI [38].

\section{The Evidence that Embolism and Hypoperfusion Are Often Linked}

Sedlaczek et al. [92] reported further experience that showed the complementary interaction of hypoperfusion and embolism. They studied 5 patients who had moyamoya occlusions of their intracranial carotid arteries and the proximal branches of the intracranial ICAs. All had had revascularization procedures on one cerebral hemisphere and had cerebral angiography as a prelude to revascularization of the unoperated cerebral hemisphere. Angiography is known to be a potent source of microemboli. A prior study had shown that the frequency of highintensity transient signals representing microemboli in patients with moyamoya disease is quite low in the absence of angiography [93]. After angiography, diffusionweighted MRI showed multiple small infarcts predominantly in the cerebral hemisphere that had not been revascularized and so was relatively hypoperfused in comparison to the operated hemisphere. Many of the infarcts were in border-zone regions [92].

Two other patients had severe intracranial venous occlusions and cardiac embolic sources [92]. Venous occlusive disease increases resistance to blood flow and, if arterial pressure and blood flow are not increased, relative hypoperfusion develops. One patient had frontal headaches for 3 days followed by the sudden onset of aphasia. Evaluation showed an occlusion of the left transverse dural sinus and atrial fibrillation. Diffusion-weighted imaging showed two small infarcts most compatible with embolism in the left cerebral hemisphere on the side of the dural sinus occlusion. Another patient who had 10 days of headache followed by sudden-onset left hemiparesis had occluded right cerebral veins and the right MCA. Evaluation showed a patent foramen ovale and an atrial septal aneurysm as the source of embolic occlusion of the right MCA. She had multiple small embolic infarcts on diffusion-weighted MRI [92]. 


\section{How Can the Association of Ischemic Strokes with Hypoperfusion Be Tied in with the Dominance of Embolism in Explaining the Pathophysiology of Ischemic Stroke?}

There are three possible interpretations of the evidence that embolism and hypoperfusion are concurrently found: (1) That the two conditions, both rather frequent, just happen to co-occur and are unrelated and not complementary. (2) That hypoperfusion promotes thromboemboli formation. Severe occlusive lesions cause hypoperfusion and the resulting changes in the amount and turbulence of blood flow promotes the formation of both white and red thrombi that form the substance of emboli. (3) That the two conditions are complementary. Low perfusion pressure and related changes in the dynamics of blood flow in the cerebral arteries affect the clearance and destination of embolic particles.

Unrelated co-occurrence of hypoperfusion and embolism would not explain the distribution of infarction in arterial border zones. Undoubtedly the severity of arterial stenosis does affect production of microemboli. Narrowing of cervicocranial arterial lumens and intimal and endothelial abnormalities stimulate formation of thrombi. Occlusive thrombi further reduce blood flow and brain perfusion. Freshly formed thrombi often embolize.

But again this simple increase in formation of thrombi would not explain the border-zone distribution of in- farction or the importance of hypoperfusion and collateral circulation in relation to brain infarction in patients who have had cardiac surgery or thrombolytic treatment.

The most important evidence that microembolism and hypoperfusion are interrelated and complementary comes from the frequent distribution of infarction to border-zone regions when these two mechanisms co-occur. Physical factors are clearly important in the formation, lysis, clearance, and washout of thromboemboli. Blood flow at arterial bifurcations is complex even in normal nonstenotic arteries. Eddies, turbulence, flow separation, and vortices are common and vary with location along the arteries [94-96]. As an artery narrows, blood flow velocity increases within the center of the artery and flow separation becomes more prominent. Flow is reduced in some parts of the artery especially on the outer perimeter of the residual lumen. When subtotal or complete occlusion of an artery develops, the blood stream flow diminishes because of reduced volume of flow and blood flow velocity also is decreased. Antegrade perfusion becomes less effective. This reduced perfusion and pressure decrease washout and throughput of emboli especially in remote border-zone portions of the brain circulation. Hypoperfusion and embolism are co-travelers that interact and complement each other to promote and enhance brain infarction.

\section{References}

$\longrightarrow 1$ Hennerici M, Hülsbömer HB, Hefter H, Lammerts D, Rautenberg W: Natural history of asymptomatic extracranial arterial disease: results of a long-term prospective study. Brain 1987;110:777-791.

-2 Fisher CM: Lacunes, small deep cerebral infarcts. Neurology 1965;15:774-784.

-3 Fisher CM: The arterial lesions underlying lacunes. Acta Neuropathol 1969;12:1-15.

-4 Fisher CM, Caplan LR: Basilar artery branch occlusion: a cause of pontine infarction. Neurology 1971;21:900-905.

5 Fisher CM: Bilateral occlusion of basilar artery branches. J Neurol Neurosurg Psychiatry 1977; 40:1182-1189.

-6 Caplan LR: Intracranial branch atheromatous disease: a neglected, understudied and underused concept. Neurology 1989;39:1246-1250.

7 Klein IF, Lavallee PC, Schouman-Claeys E, Amarenco P: High-resolution MRI identifies basilar artery plaques in paramedian pontine infarcts. Neurology 2005;64:551-552.
Thijs VN, Albers GW: Symptomatic intracranial atherosclerosis: outcome of patients who fail antithrombotic therapy. Neurology 2000; 55:490-497.

9 Kern R, Steinke W, Daffertshofer M, Prager R, Hennerici M: Stroke recurrences in patients with symptomatic versus asymptomatic middle cerebral artery disease. Neurology 2005, in print.

10 Klijn CM, Kappelle LJ, Algra A, van Gijn J: Outcome in patients with symptomatic occlusion of the intracranial carotid artery or intracranial arterial lesions: a meta-analysis of the role of baseline characteristics and types of antithrombotic treatment. Cerebrovasc Dis 2001; 12:228-234.

11 Keller H, Meier W, Yonekawa Y, Kumpe D: Noninvasive angiography for the diagnosis of carotid artery disease using Doppler ultrasound (carotid artery Doppler). Stroke 1976;7: 354-363.
12 Hennerici MG, Neuerburg-Heusler D: Vascular Diagnosis with Ultrasound. Stuttgart, Thieme, 2006, pp 1-366.

13 Fisher CM, Adams R: Observations on brain embolism with special reference to the mechanism of hemorrhagic infarction. J Neuropathol Exp Neurol 1951;10:92-93.

14 Lodder J, Krijne-Kubat B, Broekman J: Cerebral hemorrhagic infarction at autopsy: cardiac embolic cause and the relationship to the cause of death. Stroke 1986;17:626-629.

15 Hart RG, Easton JD: Hemorrhagic infarcts. Stroke 1986;17:586-589.

16 Timsit SG, Sacco RL, Mohr JP, et al: Brain infarction severity differs according to cardiac or arterial embolic source. Neurology 1993;43: 728-733.

17 Caplan LR: Brain embolism; in Caplan LR, Hurst JW, Chimowitz MC (eds): Clinical Neurocardiology. New York, Decker, pp 35-185.

$\checkmark 18$ Fisher CM: Reducing risks of cerebral embolism. Geriatrics 1979;34:59-66. 
19 Ringelstein E, Zeumer H, Angelou D: The pathogenesis of strokes from internal carotid artery occlusion: diagnostic and therapeutic implications. Stroke 1983;14:867-875.

-20 Fieschi C, Argentino C, Lenzi G, et al: Clinical and instrumental evaluation of patients with ischemic stroke within the first six hours. $\mathrm{J}$ Neurol Sci 1989;91:311-322.

-21 Furlan AJ, Higashida RT, Wechsler L, et al: Intra-arterial prourokinase for acute ischemic stroke. The PROACT II study: a randomized controlled trial. Prolyse in Acute Cerebral Thromboembolism. JAMA 1999;282:20032011.

-22 Caplan LR: Brain embolism revisited. Neurology 1993;43:1281-1287.

23 Babikian V, Caplan LR: Brain embolism is a dynamic process with variable characteristics. Neurology 2000;54:797-801.

24 Markus HS: Transcranial Doppler detection of circulating cerebral emboli: a review. Stroke 1993;24:1246-1250.

25 Markus HS, Harrison MJ: Microembolic signal detection using ultrasound. Stroke 1995; 26:1517-1519.

-26 Devuyst F, Darbelley GA, Vesin JM, Kemeny V, Ritter M, Droste DW, Molina C, Serena J, Sztajzel R, Ruchat P, Lucchesi C, Dietler G, Ringelstein EB, Despland PA, Bogousslavsky $\mathrm{J}$ : Automatic classification of HITS into artifacts or solid or gaseous emboli by a wavelet representation combined with dual-gate TCD. Stroke 2001;32:2803-2809.

-27 Darbelley GA, Duff R, Vesin JM, Despland PA, Droste DW, Molina C, Serena J, Sztajzel R, Ruchat P, Karapanayiotides T, Kalangos A, Bogousslavsky J, Ringelstein EB, Devuyst G: Solid or gaseous circulating brain emboli: are they separable by transcranial ultrasound. J Cereb Blood Flow Metab 2004;24:860-868.

28 Hennerici MG, Meairs S: Refined analysis of transcranial Doppler. Lancet Neurology 2002; 1:406.

29 Daffertshofer M, Ries S, Schminke U, Hennerici M: High-intensity transient signals in patients with cerebral ischemia. Stroke 1996;27: 1844-1849.

-30 Georgiadis D, Lindner A, Manz M, et al: Intracranial microembolic signals in 500 patients with potential cardiac or carotid embolic source and in normal controls. Stroke 1997;28: 1203-1207.

- 31 Orlandi G, Parenti G, Bertolucci A, Murri L: Silent cerebral microembolism in asymptomatic and symptomatic carotid artery stenoses of low and high degree. Eur Neurol 1997;38: 39-43.

- 32 Droste DW, Dittrich R, Kerveny V, SchulteAltedorneburg G, Ringelstein EB: Prevalence and frequency of microembolic signals in 105 patients with extracranial carotid artery occlusive disease. J Neurol Neurosurg Psychiatry 1999;67:525-528.

- 33 Forteza AM, Babikian VL, Hyde C, Winter M, Pochay V: Effect of time and cerebrovascular symptoms on the prevalence of microembolic signals in patients with cervical carotid stenosis. Stroke 1996;27:687-690.
34 Siebler M, Sitzer M, Rose G, et al: Silent cerebral embolism caused by neurologically symptomatic high-grade carotid stenosis: event rates before and after carotid endarterectomy. Brain 1993;116:1005-1015.

35 Markus HS, Thomson N, Brown MM, Thomson ND: Asymptomatic cerebral embolic signals in symptomatic and asymptomatic carotid artery disease. Brain 1995;118:1005-1011.

36 Markus HS, Droste D, Brown MM: Ultrasonic detection of cerebral emboli in carotid stenosis. Lancet 1993;341:1606.

- 37 Droste DW, Junker K, Hansberg T, Dittrich R, Ritter M, Ringelstein EB: Circulating microemboli in 33 patients with intracranial arterial stenosis. Cerebrovasc Dis 2002;13:26-30.

38 Wong KS, Gao S, Chan YL, et al: Mechanisms of acute cerebral infarctions in patients with middle cerebral artery stenosis: a diffusionweighted imaging and microemboli monitoring study. Ann Neurol 2002;52:74-81.

- 39 Gao S, Wong KS, Hansberg T, Lam WWM, Droste DW, Ringelstein EB: Microembolic signal predicts recurrent cerebral ischemic events in acute stroke patients with middle cerebral artery stenosis. Stroke 2004;35:2832-2836.

40 Segura T, Serena J, Molins A, Davalos A: Clusters of microembolic signals: a new form of cerebral microembolism in a patient with middle cerebral artery stenosis. Stroke 1998;29:722724.

41 Moody DM, Bell MA, Challa VR, et al: Brain microemboli during cardiac surgery or aortography. Ann Neurol 1990;28:477-486.

42 Hennerici M: High intensity transcranial signals (HITS): a questionable 'jackpot' for the prediction of stroke risk. J Heart Valve Dis 1994;3:124-125.

43 Barbut D, Caplan LR: Brain complications of cardiac surgery. Current Problems in Cardiology. St Louis, Mosby-Yearbook Publishers, 1997, vol 22, pp 445-476.

44 Barbut D, Lo Y, Gold JP, et al: Impact of embolization during coronary artery bypass grafting on outcome and length of stay. Ann Thor Surg 1997;63:998-1002.

-45 Daffertshofer M, Ries S, Schminke U, Hennerici $\mathrm{M}$ : High intensity signals in patients with cerebral ischemia. Stroke 1999;30:1977_ 1981.

46 Bendszus M, Koltzenburg M, Burger R, Warmuth-Metz M, Hofmann E, Solymosi L: Silent embolism in diagnostic cerebral angiography and neurointerventional procedures: a prospective study. Lancet 1999;354:1594-1597.

47 Chambers BR, Norris JW: Outcome in patients with asymptomatic neck bruits. $\mathrm{N}$ Engl J Med 1986;315:860-865.

48 North American Carotid Endarterectomy Trial collaborators: Beneficial effect of carotid endarterectomy in symptomatic patients with high-grade carotid stenosis. N Engl J Med 1991;325:445-453.

49 European Carotid Surgery Trialists Collaborator Group: MRC European Carotid Surgery Trial: interim results for symptomatic patients with severe (70-99\%) and with mild (0-29\%) carotid stenosis. Lancet 1991;337:1235-1243.
50 Nicolaides A, Kalodiki E, Ramaswami G, et al: The significance of cerebral infarcts on CT scans in patients with transient ischemic attacks; in Bernstein EF, Callow AD, Nicolaides AJ, Shifrin EG (eds): Cerebral Revascularisation. London, Med-Orion, 1993, pp 159-178.

51 Lodder J, Hupperts R, Boreas A, Kessels F: The size of territorial brain infarction on $\mathrm{CT}$ relates to the degree of internal carotid artery obstruction. J Neurol 1996;243:345-349.

-52 Executive Committee for the Asymptomatic Carotid Atherosclerosis Stenosis Study (ACAS): Endarterectomy for asymptomatic carotid artery stenosis. JAMA 1995;273:14211428.

53 Halliday A, Mansfield A, Marro J: MRC Asymptomatic Carotid Surgery Trial (ACST) Collaborative Group: Prevention of disabling and fatal strokes by successful carotid endarterectomy in patients without recent neurological symptoms: randomised controlled trial. Lancet 2004;363:1491-1502.

-54 Wechsler LR, Kistler JP, Davis KR, et al: The prognosis of carotid siphon stenosis. Stroke 1986:17:714-718.

55 Kuhnen J, Steinke W, Rautenberg W, Hennerici M: Prognosis of symptomatic and asymptomatic atherosclerotic middle cerebral artery stenosis. Cerebrovasc Dis 1995;5:258.

56 Caplan LR: Posterior Circulation Disease: Clinical Findings, Diagnosis, and Management. Boston, Blackwell, 1996.

57 Ringelstein EB, Sievers C, Ecker S, et al: Noninvasive assessment of $\mathrm{CO}_{2}$-induced cerebral vasomotor response in normal individuals and patients with internal carotid artery occlusions. Stroke 1988;19:963-969.

-58 Bisschops RH, Klijn CJ, Kappelle LJ, van Huffelen AC, van der Grond J: Association between impaired carbon dioxide reactivity and ischemic lesions in arterial border zone territories in patients with unilateral internal carotid artery occlusion. Arch Neurol 2003;60:229233.

-59 Bisschops RH, Klijn CJ, Kappelle LJ, van Huffelen AC, van der Grond J: Prevalence and volume of internal border zone lesions in patients with impaired cerebral carbon dioxide vasomotor reactivity. Arch Neurol 2003;60: 1233-1236.

60 Kleiser B, Widder B: Course of carotid artery occlusions with impaired cerebrovascular reactivity. Stroke 1992;23:171-174.

61 Ringelstein EB, Biniek R, Weiller C, et al: Type and extent of hemispheric brain infarction and clinical outcome in early and delayed middle cerebral artery recanalization. Neurology 1992;42:289-298.

62 von Kummer R, Forsting M: Effects of recanalization and collateral blood supply on infarct extent and brain edema after middle cerebral artery occlusion. Cerebrovasc Dis 1993;3:252255.

63 Jansen O, von Kummer R, Forsting M, et al: Thrombolytic therapy in acute occlusion of the intracranial internal carotid artery bifurcation. AJNR 1995; 16:1977-1986. 
64 Brucker AB, Potuschak H, Laich E, et al: Relation of thrombolytic reperfusion and collateral circulation to outcome in patients suffering cerebral main artery occlusion; in del Zoppo GJ, Mori E, Hacke W (eds): Thrombolytic Therapy in Acute Ischemic Stroke II. Berlin, Springer, 1993, pp 288-293.

65 von Kummer R, Brandt T, Mueller-Kueppers M, et al: Thrombolytic therapy of basilar artery occlusion: predictions for recanalization and good clinical outcome; in Yamaguchi T, Mori E, Minematsu K, del Zoppo GJ (eds): Thrombolytic Therapy in Acute Ischemic Stroke III. Tokyo, Springer, 1995, pp 343-348.

66 Brandt T, von Kummer R, Mueller-Kueppers M, Hacke W: Thrombolytic therapy of acute basilar artery occlusion: variables affecting recanalization and outcome. Stroke 1996;27: 875-881.

67 Tufo HM, Ostfeld AM, Shekelle R: Central nervous system dysfunction following openheart surgery. JAMA 1970;212:1333-1340.

-68 Stockard JJ, Bickford RG, Schauble JF: Pressure-dependent cerebral ischemia during cardiopulmonary bypass. Neurology 1973;23: 521-529.

-69 Gold JP, Charlson ME, Williams-Russo P, et al: Improvement of outcomes after coronary artery bypass: a randomized trial comparing intraoperative high vs low mean arterial pressure. J Thorac Cardiovasc Surg 1995;110: 1302-1314.

70 Mohr JP: Neurological complications of cardiac valvular disease and cardiac surgery including systemic hypotension; in Vinken $\mathrm{P}$, Bruyn G (eds): Handbook of Clinical Neurology, vol 38. Neurological Manifestations of Systemic Disease, pt I. Amsterdam, North Holland, 1979, pp 143-171.

71 Zülch K: On the circulatory disturbances in the borderline zones of the cerebral and spinal vessels; in Proc 2nd Int Congr on Neuropathol, vol 8. Amsterdam, Excerpta Medica, 1955, pp 894-895.

72 Zülch KJ, Behrend $\mathrm{CH}$ : The pathogenesis and topography of anoxia, hypoxia and ischemia of the brain in man; in Meyer JS, Gastaut H (eds): Cerebral Anoxia and the Electroencephalogram. Springfield, Thomas, 1961, pp 144163.
73 Romanul F, Abramowicz A: Changes in brain and pial vessels in arterial border zones. Arch Neurol 1974; 11:40-65.

74 Bogousslavsky J, Moulin T: Border-zone infarcts; in Bogousslavsky J, Caplan LR (eds): Stroke Syndromes. New York, Cambridge University Press, 1995, pp 358-365.

75 van Laar PJ, Hendrikse J, Golay X, Lu H, van Osch MJ, van der Grond J: In vivo flow territory mapping of major brain feeding arteries. Neuroimage 2005;9(in press).

76 van der Zwan A, Hillen B, Tulleken CA, Dujovny M: A quantitative investigation of the variability of the major cerebral arterial territories. Stroke 1993;24:1951-1959.

77 Szabo K, Kern R, Gass A, et al: Acute stroke patterns in patients with internal carotid artery disease: a diffusion-weighted magnetic resonance imaging study. Stroke 2001;32:13231329.

78 Hennerici M, Daffertshofer M, Jakobs L: Failure to identify cerebral infarct mechanisms from topography of vascular territory lesions. AJNR Am J Neuroradiol 1998; 19:10671074.

79 Ringelstein EB, Stoegbauer F: Border zone infarcts; in Bogousslavsky J, Caplan LR (eds): Stroke Syndromes, ed 2. Çambridge, Cambridge University Press, 2001, pp 564-582.

80 Bogousslavsky J, Regli F: Borderzone infarctions distal to internal carotid artery occlusion: prognostic implications. Ann Neurol 1986;20: 346-350.

81 Bogousslavsky J, Regli F: Unilateral watershed cerebral infarcts. Neurology 1986;36:373377.

82 Hupperts RMM, Lodder J, Wilmink J, Boiten J, Heuts-van Raak EPM: Haemodynamic mechanism in small borderzone infarcts. Cerebrovasc Dis 1993;3:231-235.

83 Price DL, Harris J: Cholesterol emboli in cerebral arteries as a complication of retrograde aortic perfusion during cardiac surgery. Neurology 1970;20:1209-1214.
84 Beal MF, Williams RS, Richardson EP, Fisher CM: Cholesterol embolism as a cause of transient ischemic attacks and cerebral infarction. Neurology 1981;31:860-865.

-85 Masuda J, Yutani C, Ogata J, Kuriyama Y, Yamaguchi T: Atheromatous embolism in the brain: a clinicopathologic analysis of 15 autopsy cases. Neurology 1994;44:1231-1237.

86 McKibbin DW, Bulkley BH, Green WR, Gott WL, Hutchins GM: Fatal cerebral atheromatous embolization after cardiac bypass. J Thorac Cardiovasc Surg 1976;71:741-745.

87 Pollanen MS, Deck JHN: The mechanism of embolic watershed infarction: experimental studies. Can J Neurol Sci 1990;17:395-398.

88 Pollanen MS, Deck JHN: Directed embolization is an alternate cause of cerebral watershed infarction. Arch Pathol Lab Med 1989;113: 1139-1141.

$>89$ Torvik A, Skullerud K: Watershed infarcts in the brain caused by microemboli. Clin Neuropathol 1982;1:99-105.

-90 Belden JR, Caplan LR, Pessin MS, Kwan E: Mechanisms and clinical features of posterior border-zone infarcts. Neurology 1999;53: 1312-1318.

$>91$ Caplan LR, Hennerici M: Impaired clearance of emboli (washout) is an important link between hypoperfusion, embolism, and ischemic stroke. Arch Neurol 1998;55:1475-1482.

92 Sedlaczek O, Caplan LR, Hennerici M: Impaired washout - embolism and ischemic stroke: further examples and proof of concept. Cerebrovasc Dis 2005;19:396-401.

93 Horn P, Lanczik O, Vajkoczy P, et al: Hemodynamic reserve and high-intensity transient signals in moyamoya disease. Cerebrovasc Dis 2005; 19:141-146.

94 Nicholls SC, Phillips DJ, Primozich JF, et al: Diagnostic significance of flow-separation in the carotid bulb. Stroke 1989;20:175-182.

95 Schmid-Schoenbein H: Arterial thrombosis as a consequence of 'quasi-chaotic' coordination of mechanical and chemical events. Cerebrovasc Dis 1995;5:102-108.

96 Schmid-Schoenbein H, Perktold K: Physical factors in the pathogenesis of atheroma formation; in Caplan LR (ed): Brain Ischemia: Basic Concepts and Clinical Relevance. London, Springer, 1995, pp 185-213. 